\title{
Epibulbar osseous choristoma: a case report
}

This article was published in the following Dove Press journal:

International Medical Case Reports Journal

13 October 2017

Number of times this article has been viewed

\section{Thendral Ponnudurai \\ Sophia Louisraj \\ Amjad Salman \\ Cornea Department, Institute of Ophthalmology, Joseph Eye Hospital, Trichy, Tamilnadu, India}

Correspondence: Thendral Ponnudurai Cornea Department, Institute of Ophthalmology, Joseph Eye Hospital, Melapudhur, Trichy 62000I, Tamilnadu, India

Tel +9l 9442398908

Email thendral_p@yahoo.co.in
Abstract: We present a case of a 15-year-old girl with an epibulbar osseous choristoma. The patient presented with a $3 \times 3 \mathrm{~mm}$, whitish, firm subconjunctival mass in the superotemporal quadrant of her right eye with vascularization. She underwent excision biopsy of the mass under topical anesthesia. The pathologic sections were consistent with a well-circumscribed osseous tissue without atypia. Osseous choristoma is one of the rare types of ocular choristoma to be considered in the differential diagnosis of pediatric epibulbar tumors.

Keywords: epibulbar osseous choristoma, subconjunctival mass, excision biopsy

\section{Introduction}

Choristomas are congenital lesions representing normal tissue(s) in an abnormal location. They are the most common epibulbar and orbital tumors in children. They can be divided into four main histopathologic groups: dermoids, lipodermoids, single-tissue choristomas, and complex choristomas. ${ }^{7}$

Osseous choristomas are rare lesions with only about 65 cases reported since 1863. They comprise compact bone surrounded by a connective tissue capsule. The predominant locations of ocular choristomas include the epibulbar region, the ocular adnexae, and the choroid. ${ }^{7}$

Epibulbar choristomas affect the cornea, limbus, or subconjunctival space. They appear mainly in the superior temporal quadrant of the episclera, between the lateral and superior rectus muscles. Their late presentation is because of their relatively asymptomatic nature and location beneath the eyelid.

We present a case of a 15-year-old girl with an epibulbar osseous choristoma of the right eye.

\section{Consent}

Written informed consent was obtained from the patient and her guardian to have her case details and the accompanying pictures published.

\section{Case history}

A 15-year-old girl was referred to our hospital for further management of a swelling in the upper and outer aspect of the right eye. She gave history of the swelling present for the past 3 years, not increasing in size with no signs of regression or a history of trauma. 
On examination, visual acuity in both eyes was $6 / 6$ $(20 / 20)$ and the eyes were orthophoric with normal extraocular movements. Pupillary reactions and intraocular pressures recorded were within normal limits.

Slit-lamp examination showed a $3 \times 3 \mathrm{~mm}$, firm, whitish, and mobile subconjunctival swelling with surrounding vascularization. There were no symptoms and signs of malignant transformation, such as rapid growth, pigmentation, presence of feeder vessels, necrosis, or ulceration (Figure 1).

With a suspected clinical diagnosis of an epibulbar dermoid and since the patient complained of constant discomfort, excision biopsy of the mass was done under topical anesthesia. After incising the conjunctiva and Tenon's capsule, the mass was removed totally and sent for histopathologic examination. The defect in the conjunctiva and Tenon's capsule was approximated with 6-0 vicryl sutures.

Hematoxylin and eosin staining was done to evaluate the mass. The histopathologic examination report showed a grayish white oval hard tissue measuring $0.7 \times 0.5 \times 0.5 \mathrm{~cm}$, with sections showing a well-circumscribed nodule of cancellous bone tissue with no evidence of atypia (Figure 2).

\section{Discussion}

In this case report, we present a rare epibulbar tumor in childhood, which is difficult to diagnose clinically. To our knowledge, this has not been previously reported in a South Asian population.

More than $30 \%$ of epibulbar tumors in childhood are choristomas. ${ }^{1}$ Choristomas account for around $25 \%$ of all conjunctival growth. ${ }^{2}$ The first case of epibulbar osseous choristoma was described by Graefe in $1863 .{ }^{3}$ After that, only about 65 cases have been reported in the literature. ${ }^{4}$

The majority of epibulbar tumors are discovered and excised by the time the patient is 14 years of age. They have been found to be twice as common in females, and preponderance for the right eye has been observed. Most of the lesions are seen in the superotemporal quadrant. ${ }^{5}$ All these factors correlate with our patient.

The differential diagnosis of osseous choristoma should include classical limbal dermoids, epithelial inclusion cysts, prolapsed orbital fat, papillomas, dermolipomas, calcified scleral plaque, and complex choristomas. Systemic conditions such as hypercalcemia, sarcoidosis, and hypervitaminosis which can produce calcification and ossification have to be considered.

Most commonly, epibulbar osteomas present as an isolated lesion within the superotemporal quadrant, but may occur in other locations on the surface of the globe, and also along with other choristomatous tissue, as much as $10 \%$ of the time. Frequently, they may involve the muscle

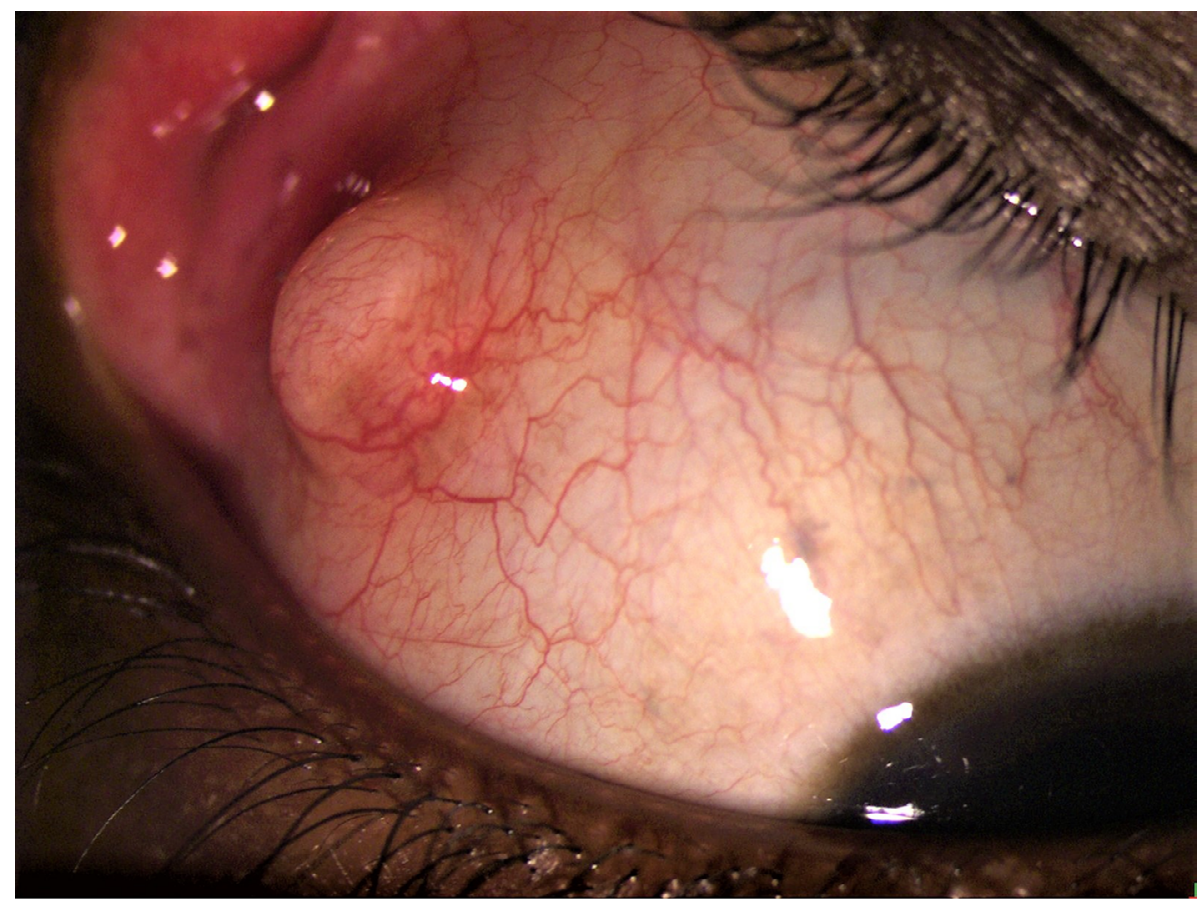

Figure I The subconjunctival mass with surrounding vascularization. 


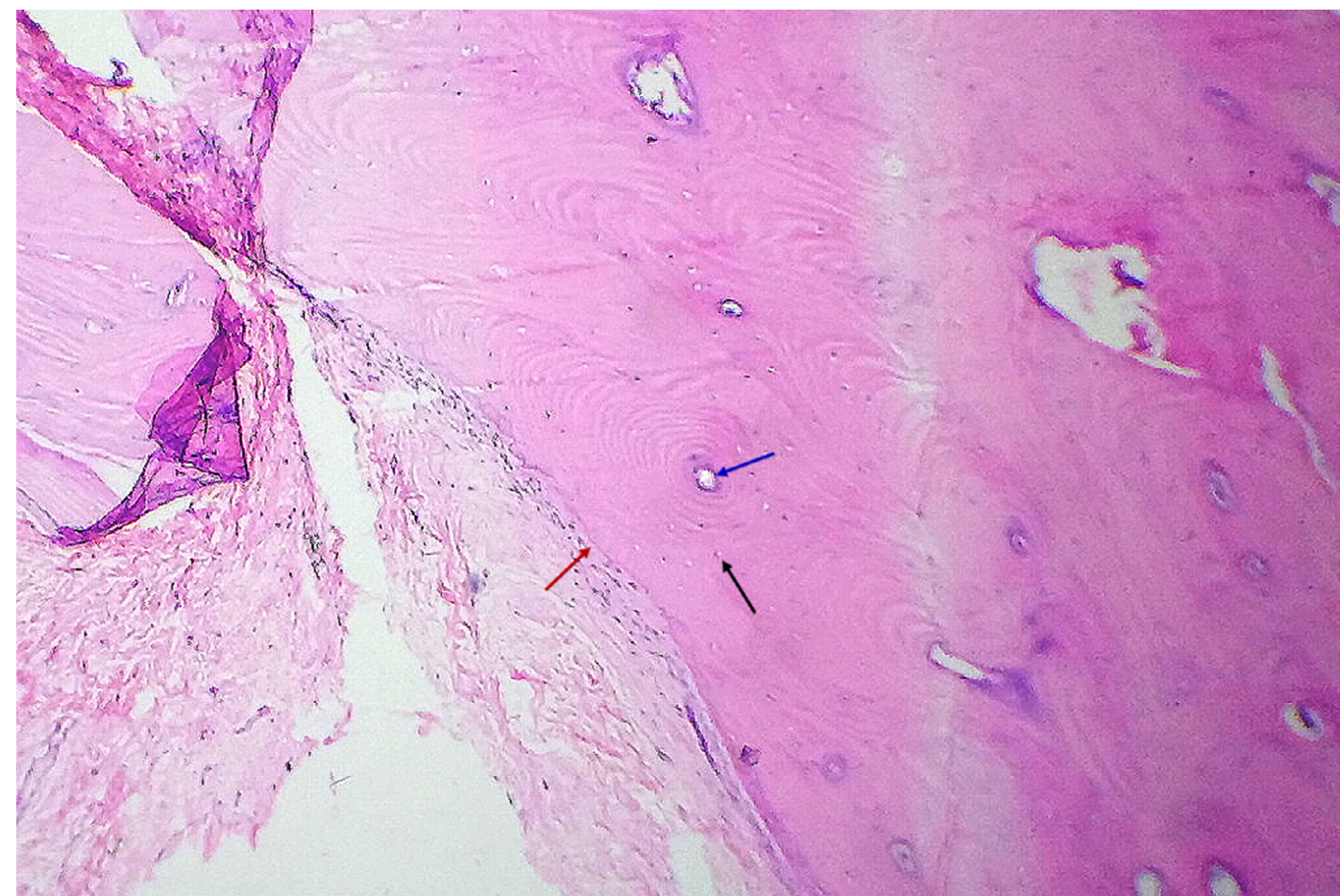

Figure 2 The pathologic section of the mass - well-defined nodule of the bone tissue with Haversian canals and surrounding lamellae (blue arrow) and osteocytes (black arrow). The junction between the conjunctiva and bone tissue is shown by a red arrow.

or have dense attachments to the underlying sclera. Osseous choristomas most likely represent congenital lesions with a potential for slow growth, but may occur in association with trauma. ${ }^{6}$

Malignant degeneration and intraocular extension of choristomas have not been reported.

\section{Conclusion}

Osseous choristoma, though rarely encountered, should be considered in the differential diagnosis of a pediatric conjunctival nodule.

\section{Acknowledgment}

We would like to thank Dr Lalitha Rani MD for providing pathologic sections.

\section{Disclosure}

The authors report no conflicts of interest in this work.

\section{References}

1. Elsas FJ, Green WR. Epibulbar tumors in childhood. Am J Ophthalmol. 1975;79(6):1001-1007.

2. Cunha RP, Cunha MC, Shields JA. Epibulbar tumors in children: a survey of 282 biopsies. J Pediatr Ophthalmol Strabismus. 1987;24(5):249-254.

3. Graefe AV. Tumor im submucosen gewebe lid-binde-haut von eigentümlicher, beschaffenheit [Tumor in the submucosa tissue lidbindehaut of peculiar, texture]. Klin Monatsbl Augenheilkd. 1863:151. German.

4. Vachette M, Moulin A, Zografos L, Schalenbourg A. Epibulbar osseous choristoma: a clinicopathological case series and review of the literature. Klin Monatsbl Augenheilkd. 2012;229(4):420-423.

5. Ortiz JM, Yanoff M. Epipalpebral conjunctival osseous choristoma. $\mathrm{Br}$ J Ophthalmol. 1979;63(3):173-176.

6. Gayre GS, Propia AP, Dutton JJ. Epibulbar osseous choristoma: case report and review of the literature. Ophthalmic Surg Lasers. 2002;33:410-415.

7. Mansour AM, Barber JC, Reinecke RD, Wang FM. Major Review: Ocular choristomas. Surv Ophthalmol. 1989;33(5):339-358.

\section{Publish your work in this journal}

The International Medical Case Reports Journal is an international, peer-reviewed open-access journal publishing original case reports from all medical specialties. Previously unpublished medical posters are also accepted relating to any area of clinical or preclinical science. Submissions should not normally exceed 2,000 words or
4 published pages including figures, diagrams and references. The manuscript management system is completely online and includes a very quick and fair peer-review system, which is all easy to use. Visit $\mathrm{http}: / /$ www.dovepress.com/testimonials.php to read real quotes from published authors. 